\title{
SETTLEMENT AND TRANSPORTATION IN THE CANADIAN NORTH
}

\author{
G. W. Rowley*
}

\begin{abstract}
Settlement
B EFORE the European penetration into the north, the native peoples lived by hunting and fishing. They were nomadic, following the animals on which they depended. Some places, such as important caribou river crossings, were particularly favourable for game and were visited regularly at certain periods of the year. Where winter sealing was good or where walrus were plentiful, semi-permanent camps were established, but the need and desire to obtain a variety of food and materials kept the individual families nomadic, or at least prevented them from settling down throughout the year at one place.

This pattern of life was disturbed by the fur trade. Posts were established in proximity to good fur trapping areas so that fur could be exchanged for trade goods. The exact sites chosen depended largely on the requirements of water transportation. Inland posts were on rivers, and coastal posts were located where there were good harbours for discharge of cargo from supply ships. For the native peoples the rifle and other imported equipment made hunting easier, and time could be spared for trapping. They visited the trading post in their region at least once a year and usually a few families settled permanently at the post. When missions, police detachments, schools, and meteorological stations were established in the north, it was usually at the trading posts, which received supplies regularly and were already to some extent centres of population. As a result small settlements grew up, but their locations depended in the first instance solely on their suitability for the fur trade. Frequently this has resulted in no difficulty, but in other cases problems have developed with the growth of the settlements. For instance, most posts were established before there was any thought of aviation. In recent years the importance of aircraft has been emphasized as an auxiliary means of normal transportation, as a way of meeting emergencies caused by epidemics and accidents, and as a convenience for inspecting parties and scientists. A small northern community requires at least a place where float-equipped aircraft in summer and ski-equipped aircraft in winter can land. Larger communities need an area suitable for development as an all-weather strip. At some of the old settlements these cannot be found.
\end{abstract}

*Secretary, Advisory Committee on Northern Development, Department of Northern Affairs and National Resources, Ottawa, Canada. 
There are many other problems which may result from the growth of a settlement. The water supply, sufficient for a few people, may prove too limited for a larger population, there may be few suitable building sites, or the disposal of sewage may be so difficult that there are serious public health problems. These problems may become so acute that the only real solution lies in moving the whole settlement to a better site. This is always a difficult decision to reach as growth is usually gradual, and less expensive measures can often be found to meet the immediate need. An example is Aklavik where a large settlement has grown in the past thirty years on a site that is thoroughly unsuitable. There is no possibility of developing an airfield at reasonable cost, the provision of adequate water supply and sewage disposal systems would be extremely expensive, conditions for construction are very bad, and there is no room for expansion. These conditions have forced a decision to move the whole settlement, but the move will be much more expensive than would have been the case if the decision had been made several years ago when the limitations of the site were first recognized.

It is extremely difficult to prevent the development of a situation such as that at Aklavik. Long-term planning by the various agencies concerned in the north can however indicate the areas where growth is likely, and additional activities should be centred on those settlements only which can be shown to be suitable for expansion. In recent years there have been a number of new settlements in the north arising out of the need for additional meteorological stations, or from mining activities. The importance of a careful choice of sites which will allow for future expansion as well as immediate needs, cannot be over-emphasized. Expert interpretation of air photographs is becoming increasingly useful in indicating the more suitable localities, but only a detailed ground survey including sampling of soil and sub-surface conditions by drilling can provide the full information required.

The development and settlement of the north will depend mainly on transportation and the mining industry. The location of mining communities will be restricted to the area of the minerals being exploited. In the case of base metals, transportation is so important a factor that exploitation in the near future can usually be expected only near to ports or to present, or easily developed, land transportation routes. There may of course be exceptions where resources are so important that the building of a whole transportation system is justified. An example is Knob Lake in Quebec where the high grade iron ore has resulted in the building of 360 miles of railway through practically uninhabited and frequently difficult country. In general, however, it seems likely that settlement will extend gradually into the north, as mineral development is made economically feasible by new transportation facilities. The mines will foster the growth of secondary industries and establish markets for local produce. This will encourage investigation of the possibilities of northern agriculture, fisheries, and the raising of livestock such as reindeer and possibly sheep.

In that part of the north too remote for economic mineral development in the near future, three main factors will affect settlement: transpolar aviation, 
military activities, and administrative needs. With the increasing use of transpolar aviation routes additional airfields and other supporting installations will be required. There will be development of a few major airfields, where terrain and meteorological conditions are suitable and supply by sea possible. A closer network of meteorological stations and aids to navigation will also be required. Military needs can be expected to result in some settlement while their logistic demands will assist in the establishment of communications and in this way accelerate the pace of economic development. In addition growing administrative services, such as schools and medical facilities for native peoples, will cause some expansion of certain settlements and a concentration of population around them. There is already a noticeable trend among the Eskimo towards larger groups and this will be accelerated by the high rate of natural increase of population shown by recent census figures, and by any success in promoting local industries.

Investigation of the problems of building research will make an important contribution to settlement in the north. Modern materials and techniques are already greatly simplifying construction problems and adding to human comfort, while permafrost research is leading to ways of avoiding the difficulties of providing suitable foundations, but much further work is required. New methods of heating, such as the possibilities of the heat pump, should be investigated. A start has been made in studying the accommodation requirements of Eskimo and the design of houses and methods of heating suited to their needs. More difficult is the establishment of a social life in isolated settlements acceptable to modern standards. This involves a wide field of social studies, including the relations between the native and white populations, the provision of adequate educational and cultural facilities, the development of responsible local government, and the fostering of interests to attract a permanent rather than a transient population. History shows that these problems can be solved by time. The Red River colony was considered by many to be in an area where no permanent settlement was possible and those who took part in the Cariboo Gold Rush packed their supplies through country which they regarded as unsuitable for agriculture and unthinkable for white women. Yet white women have succeeded in pushing their homes farther into the north whatever difficulties lay in the way. Today we should determine the problems that have been met in the past and learn how they may be solved in order to save time and prevent hardship.

Finally the role of government in the north needs constant review. There are a number of ways in which settlement can be encouraged. The value of investing in the future is recognized, but the amount that can be done in the north at any time must depend on what is desirable in relation to other demands on the economy of the country as a whole. Modification of fiscal policies, provision of subsidies and loans, increase of public services including transportation facilities and technical surveys are among the measures which can be taken to accelerate the rate of northern development, but which must be planned on sound research and knowledge of the problems. 


\section{Transportation}

In most undeveloped regions travel is difficult and this has always been the case in the north. In general the needs of the very small population have not been sufficient to justify the heavy expense of building roads and railways. There have been exceptions when some particularly valuable resource has been discovered in a comparatively inaccessible area, and has resulted in construction of a new route across difficult country, as for example the discovery of gold in the Klondike which led to the building of the White Pass and Yukon Railway through the Coastal Range. In the same way urgent strategic considerations have sometimes demanded rapid development of communications, such as the Alaska Highway, the Crimson Staging Route airfields in northeast Canada and Greenland, and the Canol pipelines and road. The Mackenzie River route, however, illustrates well how the discovery and development of resources have been influenced by the existence of a natural transportation route. On this river and its associated waterways many of the valuable resources so far known in the Canadian north have been found: the Athabasca Tar Sands, the gold of Yellowknife, the uranium of Lake Athabasca and Great Bear Lake, the oil of Norman Wells and possibly higher up the Mackenzie, the base metals at Pine Point and the east arm of Great Slave Lake, and the fish of Great Slave Lake itself.

In the north therefore the transportation routes have usually preceded the discovery and development of resources. The current mining activities along the Alaska Highway are the result of the building of the route; the highway was not built to serve these activities, and it might be a more useful highway if potential resources had been considered when it was planned. There are many other examples where the development of communications in the northern parts of the Canadian provinces has resulted in the discovery of mineral riches, for instance the silver and cobalt on the Timiskaming and Northern Ontario Railway, the rich mining district of northern Ontario and the adjacent area of Quebec along the Grand Trunk Pacific, and the nickelcopper at Sudbury on the Canadian Pacific main line. The fundamental problem of transportation in the north today is how to plan the development of facilities to serve resources, rather than to build the facilities and then find the resources as in the past; it is in fact the well-known transportation problem of putting the horse before the cart.

The first need is for adequate maps, that is, maps showing sufficient detail and of sufficient accuracy for plotting information gained by surveys. All information on the known resources must then be gathered, and those areas determined where the prospects of discovering and developing resources are most promising.

For centuries the only important resources in the north were whales and fur. Whales were over-exploited and are not at present of any significance. The fur trade still continues but trapping is not compatible with settlement, and makes comparatively small demands on transportation. There are other 
zoological resources and possible resources, fishing and reindeer herding for instance, and certain areas might be suitable for farming principally for local consumption. It is important to assess these potentialities, but there is little doubt that the main development in the north in the future will depend on the mineral and water power resources.

Unfortunately knowledge of the geology of much of the north is fragmentary. Detailed geological studies of such an enormous area can come only as a result of a sustained effort over very many years. It is possible, however, to carry out geological reconnaissance to determine the more favourable areas for prospecting much more rapidly. Of particular significance therefore is the 1952 Operation Keewatin of the Geological Survey of Canada in which the geology of an area of 57,000 square miles was determined in outline during a single season by a party with two helicopters. A similar operation, Operation Baker, was carried out in 1954 and further surveys of this sort are planned. Not only does this work direct prospecting to the more favourable areas, but it also provides information essential to the proper planning of transportation facilities, showing both the areas where transportation will most likely be required, and the eskers and other sources of engineering materials required in building facilities.

Only when much more has been found out about the resources of the north will it be possible to relate them to the main arteries into the north and to draw up a master plan for transportation construction to follow. The most promising areas should be provided with facilities for assisting detailed exploration and main routes should be planned to integrate the needs of different areas. As exploration proceeds, transportation requirements within the areas will become more definite and secondary routes can be determined. Without such a master plan, which must be constantly revised as fuller information is obtained, communication needs will be met piecemeal and some of the effort will be wasted. There is also always the possibility that military considerations will again require the construction of communications at short notice and these should, if at all possible, fit in with the master plan. In fact only in this way can the full military potentialities of the communications be realized, as the true military strength of a nation depends in large measure on the resources it controls. Similarly military needs, as far as they can be foreseen, should be considered in any plan to develop communications.

The development of a master plan based on potential resources as a guide for communications does not, of course, solve all transportation difficulties. It defines the scope of the problem, indicating the scale of facilities required and how construction should be phased, but there is still much to learn about the most satisfactory means of transportation in different conditions. The development of transportation facilities in the past and their effect on both longterm and short-term exploitation of natural resources and on the growth of secondary occupations should be examined in detail. The relative merits of railways, all-weather roads, winter roads, water transport, and air transport must be considered in each instance and the technical problems of all of these require study. 
Many of these problems lie in the field of engineering. The work done since the Second World War on permafrost and its effect on construction is an example of the type of investigation that will provide valuable information. Research on northern construction and satisfactory fuels, lubricants, batteries, and rubber for low temperature operation will make important contributions. Snow surveys are required, as well as the development of satisfactory techniques for compacting and removing snow. Much can be done to design better oversnow vehicles and sledges. There are few soundings in northern waters and it will take many years to provide the detailed hydrographic surveys required for safe navigation. Satisfactory methods of reporting and forecasting ice conditions will be of great assistance to shipping. These are only a few of many instances where transportation will benefit from the continuous improvement that can be expected as a result of research and development. Owing to their military implications many of these subjects have received continuous attention during the past few years and the results of their work will help to solve civilian as well as military problems.

In addition to the internal communications required to develop resources, there is another aspect of transportation in the north which is becoming increasingly important. It is now many years since Vilhjalmur Stefansson and others first drew attention to the advantage of great circle flights across the Arctic. The British Arctic Air Route expedition led by Gino Watkins carried out pioneer investigations in Greenland and many notable flights were made in pre-war years, especially by the Russians. The great advances in aviation and navigation during and since the Second World War overcame many of the technical difficulties, and in the post-war years long-range military flights in the Arctic have become commonplace. The lack of adequate bases in the far north, the consequent restrictions on pay-loads, and the more exacting safety requirements, however, prevented commercial exploitation of the possibilities of transpolar flights.

With the opening by the U.S.A.F. of a major base at Thule the position has changed radically. In 1952 the Scandinavian Airlines System made two experimental flights from Los Angeles to Scandinavia via Edmonton and Thule, and in June 1953 the first commercial arctic flight from Oslo to Japan via Thule and Anchorage was successfully completed. In November 1954 the Scandinavian Airlines System instituted a regular service from Los Angeles to Scandinavia via Winnipeg and Søndrestrom in Greenland, and Canadian Pacific Airlines has now begun a transpolar service from Vancouver to Amsterdam. During the next few years a number of additional commercial routes across the Arctic will probably be established, while under the bilateral air transport agreements with Canada the United Kingdom has for several years had the right to use Churchill on the route London-Prestwick-KeflavikGoose Bay-Churchill-Alaska. To support civilian operations there will be a need for additional airfields and for increases in meteorological, navigation, and radio facilities. More research will be required, especially in such fields as the meteorology of the upper air in the north and the problems of navigation in high latitudes. 
In planning the development of transportation, the interests and potentialities of the native population must not be neglected. Most interesting problems for research lie in the effect that these developments may have on the Eskimo and the part that they could play in maintaining and operating transportation facilities. Much of the north will long remain unattractive to white men, and there is a pressing need for additional sources of income for the Eskimo owing to the unprofitable condition of the fur trade, their only important economic support. If the Eskimo could take a major part in maintaining the transportation services of the north it would be of lasting benefit to them and would greatly assist the development of the north. 